\title{
BMJ Open $\omega-3$ Fatty acids for major depressive disorder in adults: an abridged Cochrane review
}

\author{
Katherine M Appleton, ${ }^{1}$ Hannah M Sallis, ${ }^{2,3}$ Rachel Perry, ${ }^{4,5}$ Andrew R Ness,,${ }^{4,5}$ \\ Rachel Churchill ${ }^{2}$
}

To cite: Appleton KM, Sallis HM, Perry R, et al. $\omega-3$ Fatty acids for major depressive disorder in adults: an abridged Cochrane review. BMJ Open 2016;6:e010172. doi:10.1136/bmjopen-2015010172

- Prepublication history for this paper is available online. To view these files please visit the journal online (http://dx.doi.org/10.1136/ bmjopen-2015-010172).

Received 2 October 2015 Accepted 21 January 2016

\section{CrossMark}

\footnotetext{
${ }^{1}$ Department of Psychology, Faculty of Science and Technology, Bournemouth University, Poole, UK ${ }^{2}$ Centre for Academic Mental Health, School of Social and Community Medicine, University of Bristol, Bristol, UK ${ }^{3}$ MRC Integrative

Epidemiology Unit, School of Social and Community Medicine, University of Bristol, Bristol, UK

${ }^{4}$ National Institute for Health Research (NIHR) Biomedical Research Unit in Nutrition, Diet and Lifestyle at the University Hospitals Bristol NHS Foundation Trust and the University of Bristol, Bristol, UK

${ }^{5}$ School of Oral and Dental Sciences, University of Bristol, Bristol, UK
}

\section{Correspondence to} Dr Katherine M Appleton; k.appleton@bournemouth.ac. uk

\section{ABSTRACT}

Objective: To assess the effects of $n-3$

polyunsaturated fatty acids (n-3PUFAs; also known as $\omega-3$ fatty acids) compared with comparator for major depressive disorder (MDD) in adults.

Design: Systematic review and meta-analyses.

Data sources: The Cochrane Depression, Anxiety and Neurosis Review Group's Specialised Registers (CCDANCTR) and International Trial Registries searched to May 2015. CINAHL searched to September 2013.

Trial selection: Inclusion criteria: a randomised controlled trial (RCT); that provided n-3PUFAs as an intervention; used a comparator; measured depressive symptomology as an outcome; and was conducted in adults with MDD.

Outcomes: Primary outcomes were depressive symptomology and adverse events.

Results: 20 trials encompassing 26 relevant studies were found. For n-3PUFAs versus placebo, n-3PUFA supplementation resulted in a small-to-modest benefit for depressive symptomology: SMD $=-0.32(95 \% \mathrm{Cl}$ -0.52 to -0.12 ; 25 studies, 1373 participants, very low-quality evidence), but this effect is unlikely to be clinically meaningful, is very imprecise and, based on funnel plot inspection, sensitivity analyses and comparison with large well-conducted trials, is likely to be biased. Considerable evidence of heterogeneity between studies was also found, and was not explained by subgroup or sensitivity analyses. Numbers of individuals experiencing adverse events were similar in intervention and placebo groups (OR=1.24, 95\% Cl 0.95 to $1.62 ; 19$ studies, 1207 participants; very low-quality evidence). For n-3PUFAs versus antidepressants, no differences were found between treatments in depressive symptomology (MD $=-0.70(95 \% \mathrm{Cl}-5.88$ to 4.48$) ; 1$ study, 40 participants, very low-quality evidence).

Conclusions: At present, we do not have sufficient evidence to determine the effects of n-3PUFAs as a treatment for MDD. Further research in the form of adequately powered RCTs is needed.

\section{BACKGROUND}

Major depressive disorder (MDD) is characterised by: depressed mood or markedly

\section{Strengths and limitations of this study}

- This review is systematic, and was conducted following Cochrane guidelines.

- All included trials are directly relevant to our research question.

- The data available to answer our research question are currently very limited, of low quality and likely to be biased.

- Our findings are imprecise and likely to be biased.

diminished pleasure or interest in all activities for a consecutive period of 2 weeks, plus the presence of four or more other symptoms; significant distress or impairment in functioning as a result of the symptoms; and an inability to attribute symptoms to the physiological effects of a substance or another medical condition. ${ }^{1}$ Highly debilitating, difficult to treat, with a high rate of recurrence, and with resultant negative impacts for both the individual and for society, ${ }^{1}$ MDD is increasing in prevalence and impact in terms of disability-adjusted life years. ${ }^{2}$

One emerging potential treatment for MDD is n-3 polyunsaturated fatty acids (n-3PUFAs), also known as $\omega-3$ fatty acids. n-3PUFAs are a family of PUFAs, named as such because of the positioning of the first double carbon bond on the third atom from the methyl end of the acyl chain. ${ }^{3}{ }^{4}$ All members of the family are derived from parent fatty acid 18:3n-3 ( $\alpha$-linolenic acid (ALA)), via desaturation and elongation. ALA, however, cannot be synthesised by humans, and thus must be obtained from the diet. ${ }^{3}{ }^{4}$ Longer chain n-3PUFAs can be formed in humans, but biological conversion is slow and inefficient, making diet an important source of these fatty acids as well. ${ }^{5}$ Dietary sources of ALA include certain nuts and seeds, such as walnuts, flaxseed and rapeseed oil. Dietary sources of the longer 
n-3PUFAs eicosapentaenoic acid (EPA) and docosahexaenoic acid (DHA) include fatty fish, some white fish, shellfish and other seafood, and certain animal products dependent on the animal's diet. ${ }^{4} 67$

Early work investigating population consumption levels of n-3PUFAs and n-3PUFA-rich foods suggested links with population levels of depressive conditions. ${ }^{8}$ Repeated studies since have also found similar associations. Within countries, n-3PUFA intakes have been negatively associated with depressive symptoms. ${ }^{9}{ }^{10}$ In clinical studies, low levels of n-3PUFAs have been found in individuals diagnosed with MDD, compared with controls, ${ }^{11}{ }^{12}$ and continuous relationships between n-3PUFA status and depressive symptoms have also been found. ${ }^{11}$ In randomised controlled trials (RCTs), beneficial effects of supplementation with n-3PUFAs compared with placebo have been reported for $\mathrm{MDD}^{13} 14$ and for other depressive disorders. ${ }^{15} 16$

Not all studies, however, report beneficial effects. Cross-sectional studies also report no associations between n-3PUFA consumption and depressive symptoms,${ }^{17} 18$ or associations explained entirely by confounders. ${ }^{19}$ Clinical studies report no associations between n-3PUFA levels and depressive symptoms, ${ }^{20-22}$ and RCTs report no benefit compared with placebo in individuals suffering from $\mathrm{MDD}^{23}$ and other depressive conditions. ${ }^{25} 26$

Reviews and meta-analyses clearly demonstrate variability between studies. ${ }^{27-31}$ Meta-analyses reveal some benefit of n-3PUFAs for depressive disorders, ${ }^{29}{ }^{30}$ but investigations of the heterogeneity also suggest differential effects of n-3PUFAs dependent on severity of depressive symptoms at baseline. ${ }^{29}$ Sensitivity analyses suggest no benefits of n-3PUFAs for individuals with mild depressive symptoms, but provide some suggestion of benefit in individuals with severe depressive symptoms. ${ }^{29}$ These findings suggest a possible benefit of n-3PUFAs for MDD.

Other reviews investigating a role for n-3PUFAs in depressive disorders have recently been conducted. ${ }^{32-35}$ These reviews typically use a broad definition of depression to include a variety of depressive disorders and conditions, in a number of populations, including children. This review considers solely major or unipolar depressive disorder, and focuses on adults.

\section{Objective}

To assess the effects of n-3PUFAs compared with comparator (eg, placebo, antidepressant treatment, standard care) for MDD in adults.

\section{METHODS}

Our review was conducted as a Cochrane review, ${ }^{36}$ and followed the methods set out in our protocol. ${ }^{37}$

\section{Study inclusion}

Only RCTs were included. Trials were included if they involved adults, regardless of participant demographics (eg, gender, age, country of residence), but we only included trials that enrolled participants with a primary diagnosis of major or unipolar depressive disorder from a trained professional or a validated rating scale, or trials that included a subgroup of these individuals. If a subgroup was used, only the data from the subgroup were included in the review, and only if the subgroup was defined and distinguished prior to randomisation. If data from diagnosed and non-diagnosed individuals were mixed, these trials were not included. Trials that enrolled participants without MDD, but with another primary psychiatric diagnosis were not included. We also excluded trials that described a diagnosis of MDD that was given only during or in relation to pregnancy. Trials were only included in the review if we were certain that all data were gained from participants with MDD. Trials were included regardless of the presence of other comorbid conditions, and regardless of participant use of adjunct therapy for depression. Trials were included if they used an exposure of n-3PUFAs as a sole or as an adjunctive therapy, regardless of the source of n-3PUFA provided, the dose, the mode of provision or duration of supplementation; and if they included a comparator, regardless of the comparator used (eg, placebo, antidepressant treatment, standard care). Our primary outcomes were: (1) depressive symptomology, assessed using any continuous validated measure of depressive symptomology; and (2) adverse events, assessed using number of individuals experiencing adverse events, as reported. Secondary outcomes of interest were: (3) depressive symptomology remission or response; (4) quality of life; and (5) failure to complete. Trials were included regardless of whether they reported on all outcomes. Measures of risk of bias were also recorded.

\section{Search methods for identification of studies}

Suitable trials for inclusion were identified by searching the Cochrane Depression, Anxiety and Neurosis Review Group's Specialised Register (CCDANCTR), CINAHL and International Trials Registers, using the search terms (depress* or dysthymi* or "affective disorder*" or "affective symptom*" or "mood disorder*" or "mental health)" AND (dha or docosahex* or eicosapent* or epa or "fatty acid*" or *ish $*$ or *inolenic $*$ or *omega ${ }^{*}$ or $n-3$ or $w-3$ or $* P U F A *$ or "cod liver oil"). There were no restrictions on date, language or publication status. We also checked the reference lists of all included trials and relevant reviews, and contacted authors of identified trials for information on unpublished or ongoing work. Searches of CCDANCTR and International Trial Registers were most recently conducted in May 2015; searches of CINAHL were most recently conducted in September 2013.

\section{Data collection}

Two review authors (HMS and RP) independently screened all titles, abstracts and all potentially relevant full-text reports to identify suitable trials for inclusion. Disagreements were resolved through discussion or 
consultation with a third person (KMA). Multiple reports of the same trials were collated, so that each trial rather than each report was the unit of interest in the review. Articles in foreign languages were obtained and translated.

Study characteristics and outcome data were extracted using a data collection form developed specifically for this work, and piloted on two trials prior to use for all others. Two review authors (HMS and KMA or RP) extracted all relevant study characteristics and outcome data. Discordances were resolved by independent abstraction and then discussion with a third author (RP or KMA, respectively). Corresponding authors were also contacted directly for relevant information. Risk of bias was assessed for each trial independently by three review authors (KMA, HMS and RP) for each domain specified in the Cochrane Handbook, ${ }^{38}$ using prespecified criteria. ${ }^{36}$ Each potential source of bias was judged to be of high, low or unclear risk. We resolved disagreements by discussion.

\section{Analysis}

Analyses were undertaken in RevMan. Analyses were undertaken per comparator to ensure combination of like with like. We analysed continuous data (following determination of similar direction where different scales were used) as standardised mean difference (SMD) with 95\% CIs, using intention-to-treat (ITT) data (based on number randomised), where possible. The SMD for all studies was calculated using Hedges' adjusted g (a formulation of effect size that includes an adjustment to correct for small sample bias ${ }^{39}$ ). Dichotomous data were collected in the form of $\mathrm{N}$ per intervention group, and were analysed as ORs with 95\% CI. Aggregated data, per study, were used. Estimates were made using random-effects models primarily, due to likely heterogeneity between studies. ${ }^{39-41}$ Fixed-effects models were also applied as sensitivity analyses. Where trials used multiple treatment groups, each treatment group was treated as an independent study (we define study either as an independent trial arm, where trials encompassed multiple arms, or as a complete trial, where only one experimental arm was involved). No trials involved individuals in more than one treatment/comparison group. Where the same comparator was used for all treatment groups, data from comparison groups were split across treatment groups, as equally as possible for analysis. Multiple treatment groups were used to allow the use of reported data (and so avoiding the use of pooling calculations) and to allow investigations of methodology where possible. Where trials used multiple time points, data from the longest follow-up period only were used for analyses. We contacted investigators in order to verify key trial characteristics and obtain missing numerical outcome data where possible. SDs which remained missing once authors had been contacted were imputed from SD data from all other trials using the same measure. ${ }^{42}$ Heterogeneity was investigated using
Higgins' I ${ }^{2}$ statistic. ${ }^{43}{ }^{44}$ Possible sources of heterogeneity were identified a priori, to include publication bias, presence/absence of comorbid conditions, use of n-3PUFAs as a sole/adjunct therapy and risk of bias. Publication bias was investigated using funnel plot asymmetry. ${ }^{41}$ Subgroup analyses were conducted using subgroups of studies to investigate effects due to the presence/ absence of comorbid conditions, and the use of n-3PUFAs as a sole/adjunct therapy, using the same methods as for the main analyses. The impact of risk of bias was assessed using sensitivity analyses, which included only the studies judged to be of low risk of (1) selection bias; (2) performance bias; and (3) attrition bias. Sensitivity analyses were also conducted to investigate differences in study methodology that were identified during the review process. Sensitivity analyses included: (1) studies using a treatment composed solely or predominantly of EPA; (2) studies using a placebo not composed of ALA; (3) studies using ITT data; (4) studies providing SDs; and (5) use of complete trials (independent studies combined) where appropriate. Results of all sensitivity analyses were compared with those of our main analyses. The quality of evidence for all outcomes was assessed using GRADE criteria, as described by the Grades of Recommendation, Assessment, Development and Evaluation Working Group. ${ }^{38}$

\section{RESULTS}

\section{Search results}

Searches identified 677 records of potential relevance to our review. Screening by title and abstract resulted in the retrieval of 153 full-text papers, and of these, 85 records were found to relate to RCTs of relevance. Full details of the search results are provided in figure 1 . Of the trials identified, Lucas et $a l^{45}$ involves individuals both with and without MDD, and participants were stratified by diagnosis for randomisation, thus we have included only the subgroup of individuals with MDD. The trial by Coryell ${ }^{46}$ includes tests of two doses of n-3PUFA (1.14 and $2.28 \mathrm{~g}$ /day), the trial by da Silva et $a t^{47}$ involves individuals who were randomised dependent on antidepressant status (antidepressant use/no antidepressant use) at trial entry, the trial by Jazayeri et $a t^{48}$ involves two separate comparator groups ( placebo/antidepressant), the trial by Mischoulon et $a t^{49}$ includes tests of two interventions (enriched EPA/ enriched DHA), and the trial by Peet and Horrobin ${ }^{50}$ includes tests of three doses of n-3PUFA (1, 2 and $4 \mathrm{~g}$ / day). In these five trials, all groups were independent, thus we have considered each as a separate study. This resulted in the inclusion in analyses of 26 independent studies, involving a total of 1458 participants-Bot et $a l^{51}$ Carney et $a l^{52}{ }^{5}$ Coryell $^{46}$ (1.14 g/day), Coryell ${ }^{46}$ (2.28 g/day), da Silva et $a l^{47}$ (AD), da Silva et $a l^{47}$ (nAD), Gertsik et $a l^{53}$ Gharekhani et $a l^{54}$ Gonzalez et al, ${ }^{55}$ Grenyer $e t a l^{23}$ Jazayeri et $a t^{48}$ (placebo), Jazayeri $e t a t^{48}$ 


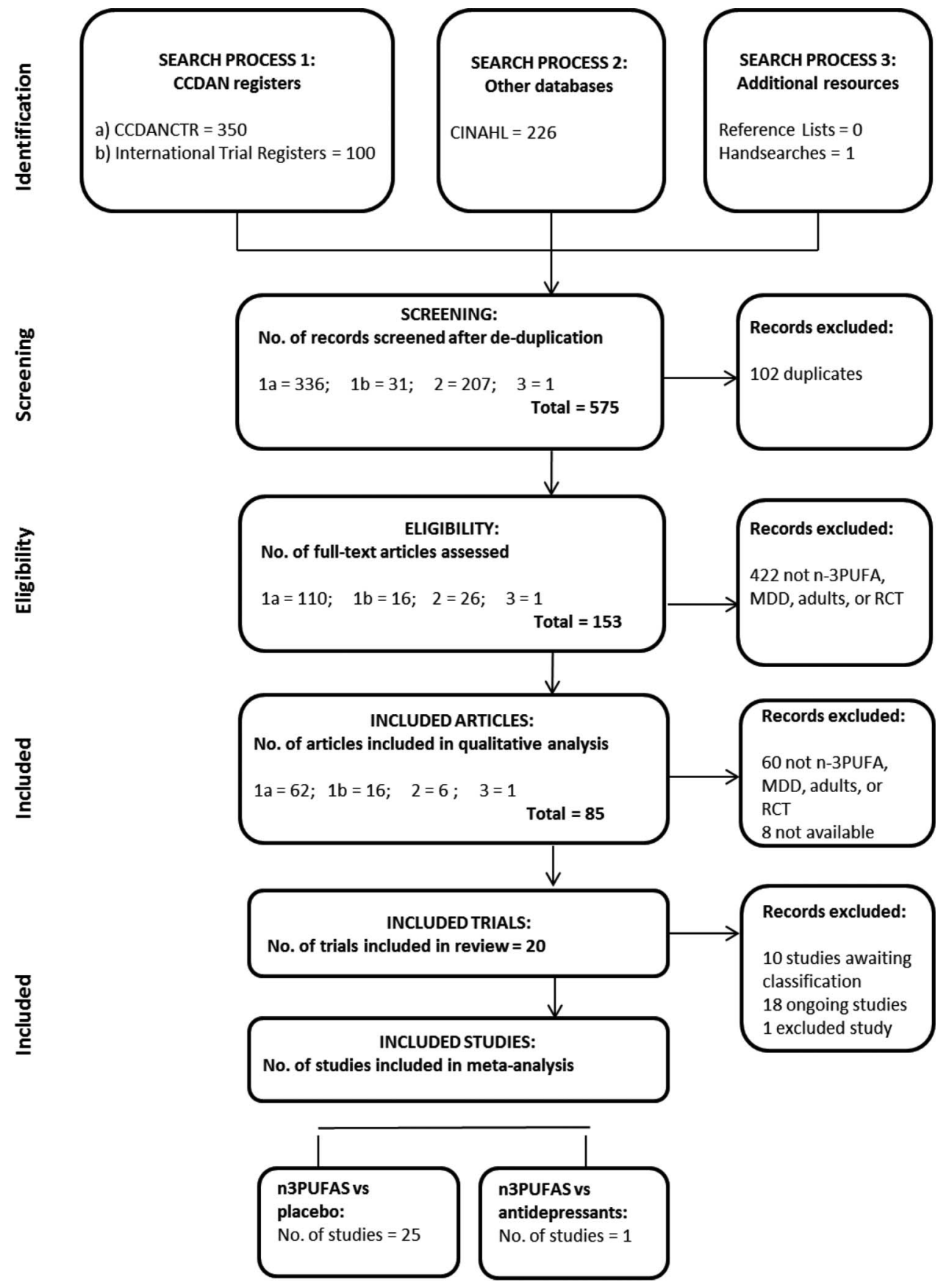

Figure 1 PRISMA diagram demonstrating the outcomes of the search process, and inclusion of studies in the review and meta-analyses. CCDANCTR, Cochrane Depression, Anxiety and Neurosis Review Group's Specialised Registers; MDD, major depressive disorder; n-3PUFA, n-3 polyunsaturated fatty acid; RCT, randomised controlled trial.

(AD), Lesperance et $a l,{ }^{56}$ Lucas $e t a l,{ }^{45}$ Marangell et $a l,{ }^{57}$ Mischoulon et $a l^{58}$ Mischoulon et $a l^{49}$ (DHA), Mischoulon et al ${ }^{49}$ (EPA), Nemets et al,,$^{13}$ Park et al, ${ }^{59}$ Peet and Horrobin ${ }^{50}(1 \mathrm{~g} /$ day $)$, Peet and Horrobin ${ }^{50}$ $(2 \mathrm{~g} /$ day $)$, Peet and Horrobin ${ }^{50}$ (4 g/day), Rondanelli et al,$^{60}$ Silvers et al, ${ }^{24} \mathrm{Su}$ et al. ${ }^{14}$

\section{Included studies}

Full characteristics of all 26 studies are provided in the Cochrane publication. ${ }^{36}$ Brief details are given in table 1.
Studies varied in sample size (from $n=5^{46}(1.14 \mathrm{~g} /$ day) to $n=432^{56}$ ), although the majority of studies were small. Only three trials ${ }^{49} 5256$ included over 100 participants. Trials were undertaken across the world, in clinical $^{14} 23484952545859$ and community settings. ${ }^{45} 4760$ The majority of participants in all studies, but two ${ }^{52} 54$ were female (range $52 \%$ female $^{51}$ to $100 \%$ female $^{4560}$ ). Mean ages ranged from $29^{46}$ to 84 years. ${ }^{60}$ Five studies included individuals with comorbidities, ${ }^{47} 515254$ three studies included individuals with no comorbidities, ${ }^{145758}$ 


\begin{tabular}{|c|c|c|c|c|c|c|c|c|c|c|}
\hline Study & $\mathbf{N}$ & Setting & $\begin{array}{l}\text { Participants } \\
\text { (gender, age) }\end{array}$ & Comorbidities & $\begin{array}{l}\text { Adjunct } \\
\text { therapy }\end{array}$ & $\begin{array}{l}\text { Intervention } \\
\text { (n-3PUFAs, } \\
\text { dose) }\end{array}$ & Comparison* & Duration & $\begin{array}{l}\text { Depressive } \\
\text { symptomology } \\
\text { measure used } \\
\text { in analyses }\end{array}$ & $\begin{array}{l}\text { Adverse } \\
\text { events } \\
\text { included in } \\
\text { analyses }\end{array}$ \\
\hline $\begin{array}{l}\text { Bot et al, } \\
2010^{51}\end{array}$ & 25 & $\begin{array}{l}\text { Clinical, The } \\
\text { Netherlands }\end{array}$ & $\begin{array}{l}52 \% \text { female, mean } \\
\text { age }=54 \text { years }\end{array}$ & $\checkmark$ & $\checkmark$ & EPA-1 g/day & $\begin{array}{l}\text { Rapeseed oil } \\
\text { +medium } \\
\text { chain } \\
\text { triglycerides }\end{array}$ & 12 weeks & MADRS & $\checkmark$ \\
\hline $\begin{array}{l}\text { Carney et al, } \\
2009^{52}\end{array}$ & 122 & $\begin{array}{l}\text { Clinical, } \\
\text { USA }\end{array}$ & $\begin{array}{l}34 \% \text { female, mean } \\
\text { age }=58 \text { years }\end{array}$ & $\checkmark$ & $\checkmark$ & $\begin{array}{l}\text { EPA/DHA- } \\
0.93 / 0.75 \mathrm{~g} / \text { day }\end{array}$ & Corn oil & 10 weeks & HDRS (17 item) & $\checkmark$ \\
\hline $\begin{array}{l}\text { Coryell } \\
\text { unpublished } \\
(1.14 \mathrm{~g} / \text { day })^{46}\end{array}$ & $\begin{array}{l}11 \text { (across } \\
\text { both studies) }\end{array}$ & $\begin{array}{l}\text { Clinical/ } \\
\text { community, } \\
\text { USA }\end{array}$ & $\begin{array}{l}82 \% \text { female, mean } \\
\text { age }=29 \text { years }\end{array}$ & Possible & $\checkmark$ & $\begin{array}{l}\text { EPA/DHA- } \\
0.74 / 0.4 \mathrm{~g} / \mathrm{day}\end{array}$ & Oil & 6 weeks & MADRS & $\checkmark$ \\
\hline $\begin{array}{l}\text { Coryell } \\
\text { unpublished } \\
(2.28 \mathrm{~g} / \text { day })^{46}\end{array}$ & $\begin{array}{l}11 \text { (across } \\
\text { both studies) }\end{array}$ & $\begin{array}{l}\text { Clinical/ } \\
\text { community, } \\
\text { USA }\end{array}$ & $\begin{array}{l}82 \% \text { female, mean } \\
\text { age }=29 \text { years }\end{array}$ & Possible & $\checkmark$ & $\begin{array}{l}\text { EPA/DHA- } \\
1.48 / 0.8 \mathrm{~g} / \text { day }\end{array}$ & Oil & 6 weeks & MADRS & $\checkmark$ \\
\hline $\begin{array}{l}\text { da Silva et al, } \\
2005(A D)^{47}\end{array}$ & $\begin{array}{l}31 \text { (across } \\
\text { both studies) }\end{array}$ & $\begin{array}{l}\text { Community, } \\
\text { Brazil }\end{array}$ & $\begin{array}{l}58 \% \text { female, mean } \\
\text { age }=64 \text { years }\end{array}$ & $\checkmark$ & $\checkmark$ & $\begin{array}{l}\mathrm{EPA} / \mathrm{DHA}- \\
0.72 / 0.48 \mathrm{~g} / \text { day }\end{array}$ & Mineral oil & 12 weeks & MADRS & $\checkmark$ \\
\hline $\begin{array}{l}\text { da Silva et al, } \\
2005 \text { (nAD) }^{47}\end{array}$ & $\begin{array}{l}31 \text { (across } \\
\text { both studies) }\end{array}$ & $\begin{array}{l}\text { Community, } \\
\text { Brazil }\end{array}$ & $\begin{array}{l}58 \% \text { female, mean } \\
\text { age }=64 \text { years }\end{array}$ & $\checkmark$ & $x$ & $\begin{array}{l}\mathrm{EPA} / \mathrm{DHA}- \\
0.72 / 0.48 \mathrm{~g} / \mathrm{day}\end{array}$ & Mineral oil & 12 weeks & MADRS & $\checkmark$ \\
\hline $\begin{array}{l}\text { Gertsik et al, } \\
2012^{53}\end{array}$ & 42 & $\begin{array}{l}\text { Clinical/ } \\
\text { community, } \\
\text { USA }\end{array}$ & $\begin{array}{l}\text { unknown gender } \\
\text { distribution, mean } \\
\text { age }=41 \text { years }\end{array}$ & Possible & $\checkmark$ & $\begin{array}{l}\text { EPA/DHA/other } \\
\text { n-3PUFAs- } \\
1.8 / 0.4 / 0.2 \mathrm{~g} / \text { day }\end{array}$ & Olive oil & 8 weeks & HDRS (21 item) & $\checkmark$ \\
\hline $\begin{array}{l}\text { Gharekhani } \\
\text { et al, } 2014^{54}\end{array}$ & 54 & Clinical, Iran & $\begin{array}{l}\text { Completers- } 44 \% \\
\text { female, mean } \\
\text { age }=57 \text { years }\end{array}$ & $\checkmark$ & $x$ & $\begin{array}{l}\mathrm{EPA} / \mathrm{DHA}- \\
1.08 / 0.72 \mathrm{~g} / \text { day }\end{array}$ & Parrafin oil & 16 weeks & $\mathrm{BDI}$ & $\checkmark$ \\
\hline $\begin{array}{l}\text { Gonzalez } \\
\text { et al, } 2011^{55}\end{array}$ & 20 & $\begin{array}{l}\text { Setting not } \\
\text { reported, } \\
\text { Venezuela }\end{array}$ & $\begin{array}{l}\text { Completers-80\% } \\
\text { female, mean } \\
\text { age }=39 \text { years }\end{array}$ & Possible & $\checkmark$ & EPA-3 g/day & Not reported & 8 weeks & HDRS (17 item) & $x$ \\
\hline $\begin{array}{l}\text { Grenyer et al, } \\
2007^{23}\end{array}$ & 83 & $\begin{array}{l}\text { Clinical, } \\
\text { Australia }\end{array}$ & $\begin{array}{l}61 \% \text { female, mean } \\
\text { age }=45 \text { years }\end{array}$ & Possible & Possible & $\begin{array}{l}\text { EPA/DHA- } \\
0.56 / 2.2 \text { g/day }\end{array}$ & Olive oil & 16 weeks & HDRS (17 item) & $\checkmark$ \\
\hline 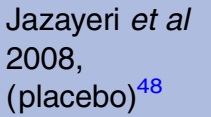 & $\begin{array}{l}60 \text { (across } \\
\text { both studies) }\end{array}$ & Clincal, Iran & $\begin{array}{l}\text { Competers-69\% } \\
\text { female, mean } \\
\text { age }=35 \text { years }\end{array}$ & Possible & $\checkmark$ & EPA-1 g/day & Rapeseed oil & 8 weeks & HDRS (24 item) & $x$ \\
\hline $\begin{array}{l}\text { Jazayeri et al, } \\
2008,(A D)^{48}\end{array}$ & $\begin{array}{l}60 \text { (across } \\
\text { both studies) }\end{array}$ & Clincal, Iran & $\begin{array}{l}\text { Competers-69\% } \\
\text { female, mean } \\
\text { age }=35 \text { years }\end{array}$ & Possible & $x$ & EPA-1 g/day & $\begin{array}{l}20 \mathrm{mg} \\
\text { fluoxetine }\end{array}$ & 8 weeks & HDRS (24 item) & $x$ \\
\hline $\begin{array}{l}\text { Lesperance } \\
\text { et al, } 2011^{56}\end{array}$ & 432 & $\begin{array}{l}\text { Clinical/ } \\
\text { community, } \\
\text { Canada }\end{array}$ & $\begin{array}{l}69 \% \text { female, mean } \\
\text { age }=46 \text { years }\end{array}$ & Possible & Possible & $\begin{array}{l}\text { EPA/DHA- } \\
1.05 / 0.15 \mathrm{~g} / \text { day }\end{array}$ & $\begin{array}{l}\text { Sunflower oil } \\
\text { plus 2\% fish } \\
\text { oil }\end{array}$ & 8 weeks & MADRS & $\checkmark$ \\
\hline $\begin{array}{l}\text { Lucas et al, } \\
2009^{45}\end{array}$ & 29 & $\begin{array}{l}\text { Community, } \\
\text { Canada }\end{array}$ & $\begin{array}{l}100 \% \text { female, } \\
\text { mean } \\
\text { age }=50 \text { years }\end{array}$ & Possible & $x$ & $\begin{array}{l}\text { EPA/DHA- } \\
1.05 / 0.15 \mathrm{~g} / \text { day }\end{array}$ & $\begin{array}{l}\text { Sunflower oil } \\
\text { plus } 2 \% \text { fish } \\
\text { oil }\end{array}$ & 8 weeks & HDRS (21 item) & $\checkmark$ \\
\hline
\end{tabular}




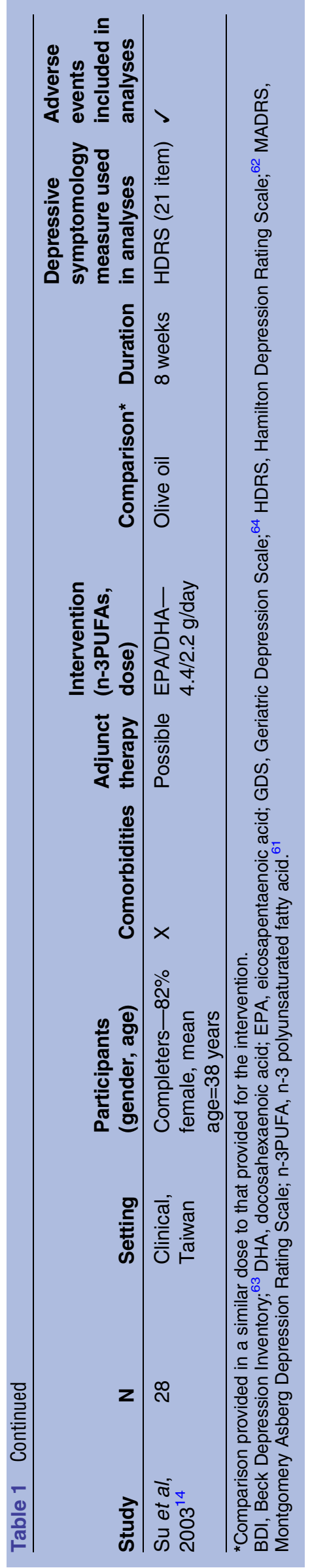

while all other studies included a mix. Twelve studies included individuals who were all receiving adjunct therapy at the time of the trial, ${ }^{46}{ }^{47}(\mathrm{AD}),{ }^{48}$ (placebo), ${ }^{50-53} 55 \quad 59$ seven studies included individuals who were all not receiving adjunct therapy, ${ }^{45}{ }^{47}$ (nAD) ${ }^{48}$ $(\mathrm{AD}){ }^{49} \quad 54 \quad 57$ and seven studies included a mix. $^{13} 142324565860$ Studies used either an EPA only intervention, ${ }^{13} 4850515558$ a DHA only intervention, ${ }^{57} \mathrm{EPA} /$ DHA combinations ${ }^{14232445-4752545659}$ and EPA/DHA/ other n-3PUFA combinations. ${ }^{49} 53{ }^{60}$ Doses of n-3PUFAs ranged from $1^{48} 50(1 \mathrm{~g} /$ day $),{ }^{51} 58$ to $6.6 \mathrm{~g} /$ day. ${ }^{14}$ All studies used a placebo comparator, with the exception of one study that compared n-3PUFAs with antidepressants. ${ }^{48}$ (AD) A variety of placebo comparators were used, including olive oil ${ }^{14232453}$ and paraffin oil..$^{50545860}$ In the study where n-3PUFAs were compared with antidepressants, n-3PUFAs were given using EPA only at a dose of $1 \mathrm{~g} /$ day, and compared with $20 \mathrm{mg} /$ day fluoxetine. ${ }^{48}$ (AD) Treatment duration for each study ranged from $4^{13}$ to 16 weeks. ${ }^{23} 54$ Depressive symptomology was reported using continuous data ${ }^{61-64}$ in all studies. Number of individuals experiencing adverse events were reported in 22 studies. ${ }^{13} 14232445-4749-5456$ 58-60 Risk of bias was judged to be very variable between studies. A graphical representation of all judgements is given in figure 2. Full details are provided in the Cochrane publication. ${ }^{36}$

Our searches also identified 1 trial registration that has been classified as an excluded study, ${ }^{38} 9$ RCTs that are currently awaiting classification and 16 RCTs that are currently ongoing that may be suitable for future reviews. ${ }^{36}$

\section{Effects of interventions}

\section{Comparison of n-3PUFAs with placebo}

Twenty-five studies involving 1438 individuals ${ }^{13} 142324$ 45-47 48 (placebo) ${ }^{49-60}$ compared n-3PUFAs with placebo.

Depressive symptomology was lower after n-3PUFAs compared with placebo: $\mathrm{SMD}=-0.32(95 \% \mathrm{CI}-0.52$ to -0.12), 25 studies, 1373 participants (see figure 3), but effect sizes are small-to-modest, CIs range between a very small (non-clinically beneficial) to a modest (clinically relevant) effect; there was substantial heterogeneity between studies $\left(I^{2}=59 \%\right)$, and using GRADE criteria, the quality of the evidence was judged to be very low. A SMD of 0.32 represents a difference between groups in scores on the Hamilton Depression Rating Scale (HDRS; 17 items) of approximately 2.2 (0.8 to 3.6 (95\% CI) ) points (based on the SDs reported in the trials included).

Number of individuals experiencing adverse events were similar in n-3PUFA and placebo groups-OR=1.24 (95\% CI 0.95 to 1.62 ), 19 studies, 1207 participants (see figure 4). CIs however are wide, and suggest that effects could range from a reduction in odds of having an adverse event of $5 \%$ to an increase of $62 \%$ in n-3PUFA groups compared with placebo. Using GRADE criteria, the quality of the evidence was judged 


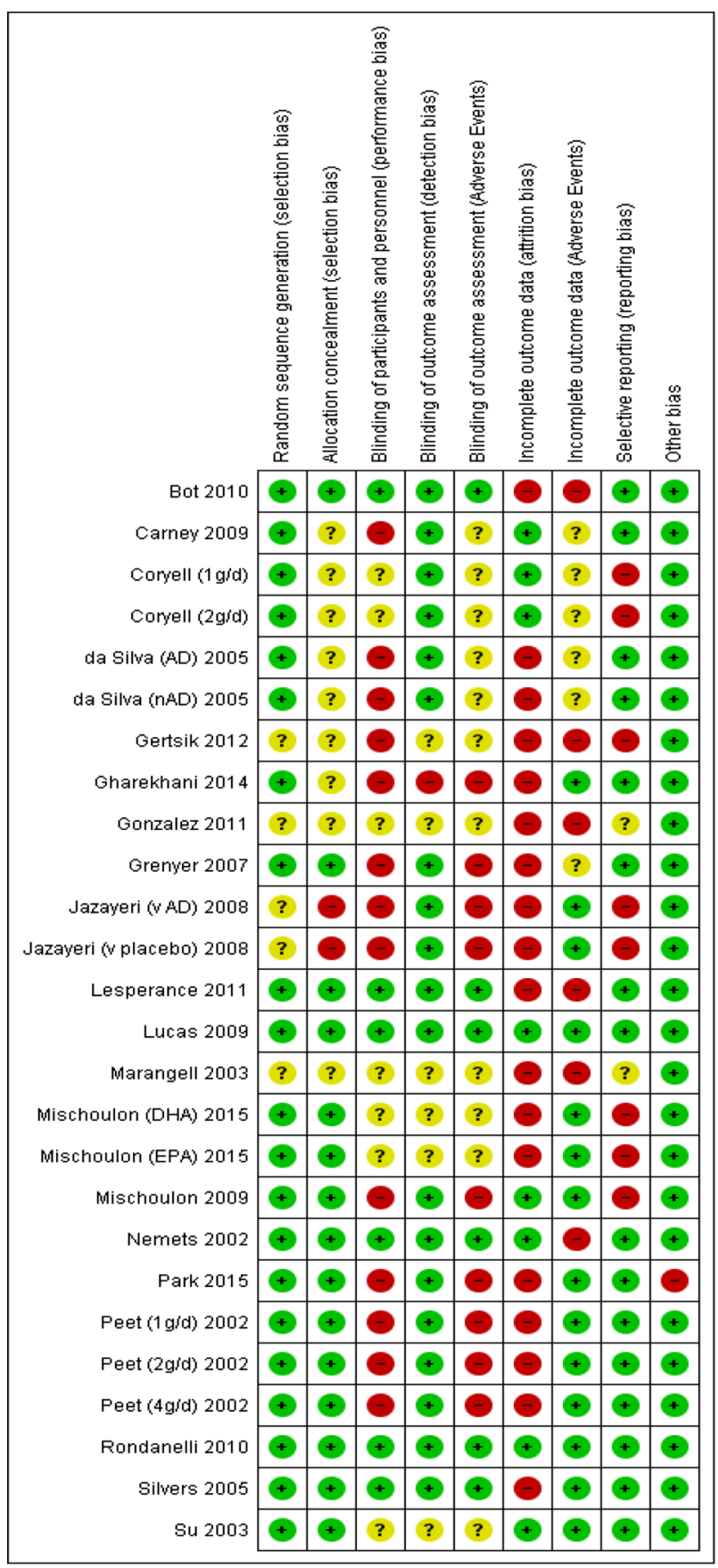

Figure 2 Judgements of risk of bias for each domain and each study in the review.

to be very low, but there was no evidence of heterogeneity between studies $\left(\mathrm{I}^{2}=0 \%\right)$. Adverse events were predominantly gastrointestinal in nature, but psychological and other physical adverse events were also reported.

Analyses on secondary outcomes are reported in our Cochrane publication. ${ }^{36}$

\section{Reporting bias}

The funnel plots for the analyses on our two primary outcomes are presented in figures 5 and 6 . These plots demonstrate some asymmetry, suggesting possible publication bias in these outcomes.

\section{Subgroup analyses}

There was a statistically significant difference for depressive symptomology between subgroups based on presence/absence/possible comorbidities $\left(\chi^{2}=7.23, \quad \mathrm{df}=2\right.$, $\mathrm{p}=0.03$ ), but the evidence of heterogeneity between subgroups was high $\left(\mathrm{I}^{2}=72 \%\right)$, and effects were not clear. There was no statistically significant difference between subgroups for adverse events $\left(\chi^{2}=0.77, \mathrm{df}=2, \mathrm{p}=0.68\right)$, and no evidence of heterogeneity between subgroups $\left(\mathrm{I}^{2}=0 \%\right)$. For subgroups based on presence/absence/ possible use of adjunct therapy, there was no statistically significant difference between subgroups for depressive symptomology $\left(\chi^{2}=1.01, \mathrm{df}=2, \mathrm{p}=0.60, \mathrm{I}^{2}=0 \%\right)$, or for adverse events $\left(\chi^{2}=2.92, \mathrm{df}=2, \mathrm{p}=0.23, \mathrm{I}^{2}=32 \%\right)$.

\section{Sensitivity analyses}

Using fixed-effects models, results are similar to those achieved using random-effects models (depressive symptomology: $\mathrm{SMD}=-0.20$ (95\% CI -0.31 to -0.09$)$; adverse events: OR=1.29 (95\% CI 0.99 to 1.67)), although effect sizes were smaller. Effect size estimates in depressive symptomology are half the size using fixed-effects models compared with using random-effects models.

Fourteen studies were judged to be of low risk of selection bias, ${ }^{13} \quad 14 \quad 23 \quad 24 \quad 4549-51 \quad 56 \quad 58-60$ six studies were judged to be of low risk of performance bias $^{13} 2445515660$ and seven studies were judged to be of low risk of attrition bias. ${ }^{13} 144546525860$ Analyses of these sets of studies demonstrate no statistical differences between n-3PUFA and placebo groups in depressive symptomology ( $\mathrm{SMD}=-0.21$ (95\% CI -0.45 to 0.03$)$; $\mathrm{SMD}=-0.14(95 \% \mathrm{CI}-0.55$ to 0.26$) ; \mathrm{SMD}=-0.39(95 \%$ CI -0.96 to 0.17 ), respectively), or in adverse events $(\mathrm{OR}=1.31(95 \%$ CI 0.98 to 1.75$) ; \mathrm{OR}=1.22(95 \%$ CI 0.85 to 1.74 ); $\mathrm{OR}=0.82$ (95\% CI 0.46 to 1.45 ), respectively). CIs, however, are wide and suggest both a possible clinically significant benefit of n-3PUFAs and a possible negligible effect compared with placebo in depressive symptomology, and a possible range of effects for n-3PUFAs in adverse events from a small reduction to a large increase, compared with placebo.

\section{Additional sensitivity analyses}

Eight studies used an intervention composed solely of EPA. ${ }^{13} 48$ (placebo $),^{50}(1 \mathrm{~g} /$ day $),{ }^{50}(2 \mathrm{~g} /$ day $),{ }^{50}(4 \mathrm{~g} /$ day), ${ }^{51} 5558$ Thirteen studies used an intervention composed predominantly of EPA. ${ }^{14} 45{ }^{46}(1 \mathrm{~g} /$ day $),{ }^{46}$ (2 g/ day) ${ }^{47}(\mathrm{AD}),{ }^{47}(\mathrm{nAD}),{ }^{49}$ (EPA),${ }^{52-54} 565960$ Nineteen studies did not use a placebo containing ALA. ${ }^{13} 1423244547$ (AD),${ }^{47}$ (nAD),${ }^{50}$ (1 g/day), ${ }^{50}$ (2 g/ day), ${ }^{50}$ ( $4 \mathrm{~g}$ /day) ${ }^{52-60}$ Analyses of these sets of studies demonstrated a modest benefit of n-3PUFAs compared with placebo for depressive symptomology $(\mathrm{SMD}=-0.45$ (95\% CI -0.74 to -0.15$)$; $\mathrm{SMD}=-0.40$ (95\% CI -0.72 to $-0.08) ; \quad \mathrm{SMD}=-0.40 \quad(95 \% \quad \mathrm{CI} \quad-0.62$ to -0.15$)$, 


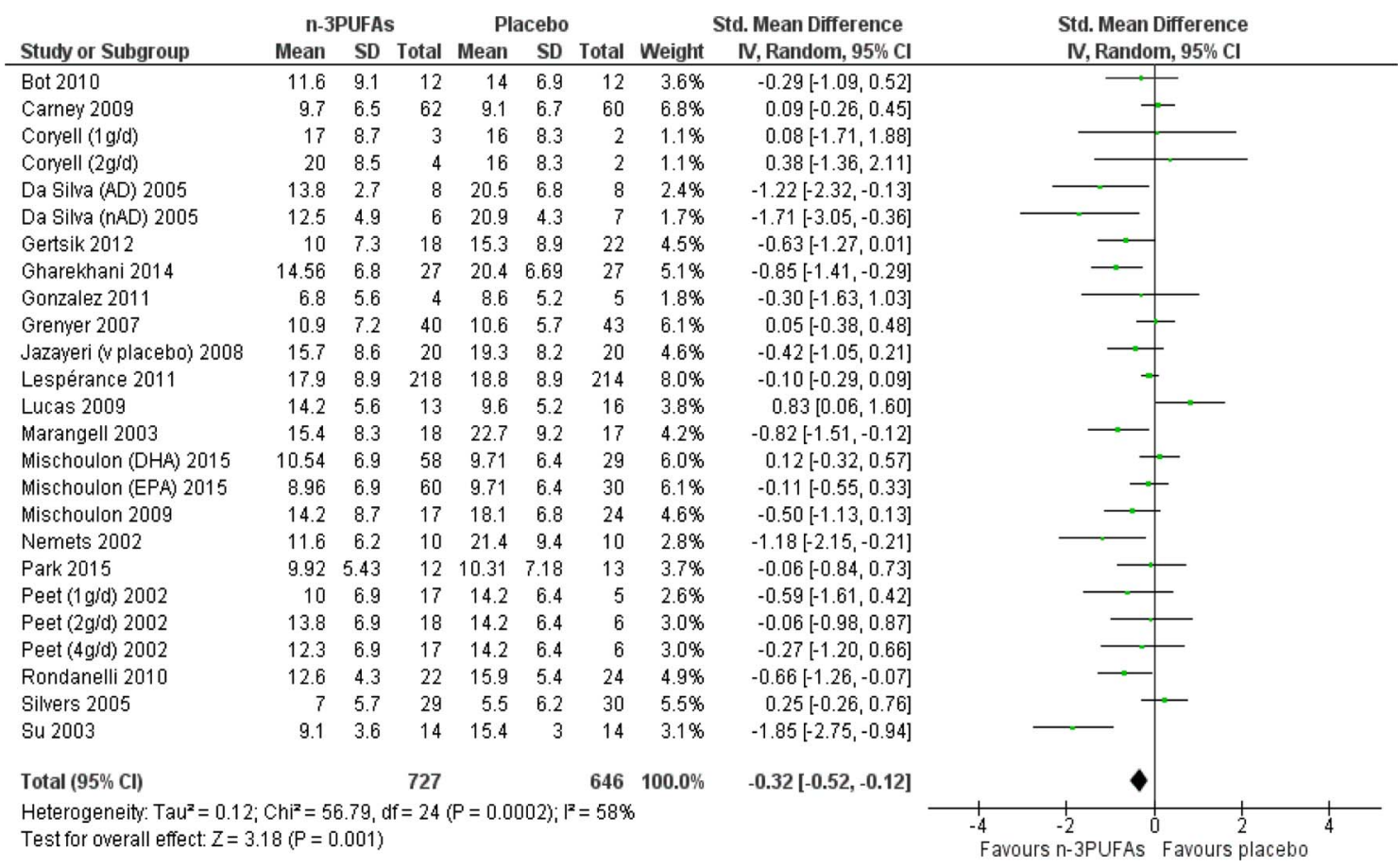

Figure 3 Forest plot for the outcome depressive symptomology (continuous) for the comparison of n-3PUFAs with placebo. DHA, docosahexaenoic acid; EPA, eicosapentaenoic acid; n-3PUFA, n-3 polyunsaturated fatty acid.

respectively) and no differences between groups for adverse events $\quad(\mathrm{OR}=0.99 \quad(95 \%$ CI 0.39 to 2.45$)$; $\mathrm{OR}=1.26(95 \%$ CI 0.88 to 1.80$)$; OR=1.14 (95\% CI 0.85 to 1.54$)$, respectively). CIs for all analyses, however, are again wide and suggest an effect size estimate for depressive symptomology that ranges from small to clinically significant, and both a possible reduction and an increase in adverse events. The overall effect size estimate for depressive symptomology was larger in these analyses than in our main analyses, but the evidence of heterogeneity between studies was also higher, except in the analyses on studies using an intervention that was solely EPA $\left(\mathrm{I}^{2}=0 \%\right)$.

Analyses of only the studies for which we had ITT data, ${ }^{13} 1423454648$ (placebo) ${ }^{52-54} 565860$ of only the studies that provided SDs, ${ }^{13} 14232445-48$ (placebo) ${ }^{51-60}$

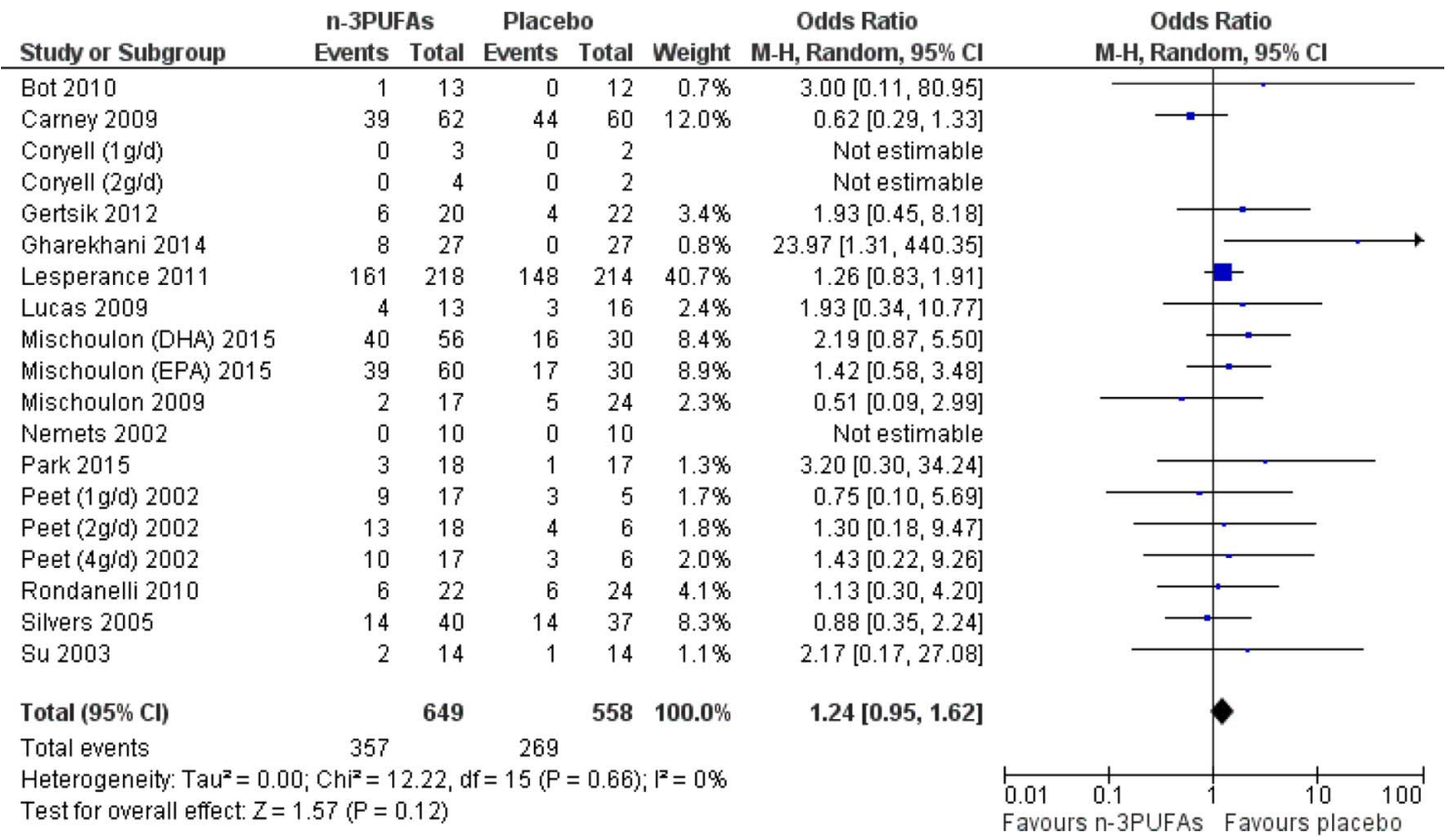

Figure 4 Forest plot for the outcome adverse events for the comparison of n-3PUFAs with placebo. DHA, docosahexaenoic acid; EPA, eicosapentaenoic acid; n-3PUFA, n-3 polyunsaturated fatty acid. 


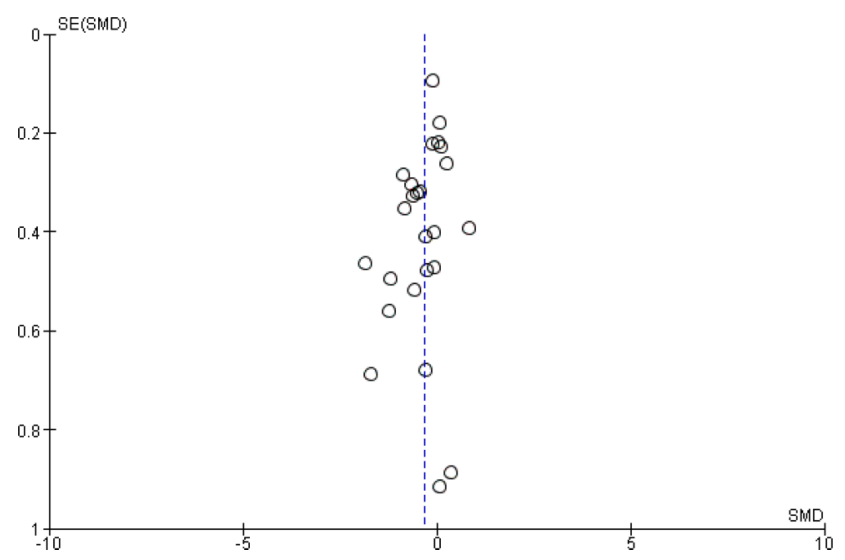

Figure 5 Funnel plot for the outcome depressive symptomology (continuous) for the comparison of $n-3$ polyunsaturated fatty acids with placebo.

and using combined studies where appropriate, reveal findings that are very comparable to those achieved in our main analyses.

\section{Comparison of n-3PUFAs with antidepressants}

Data were only available from one study (40 participants $)^{48}$ (AD) for this comparison. Depressive symptomology, based on the HDRS, was similar in n-3PUFA and antidepressant groups: $\mathrm{MD}=-0.70(95 \% \mathrm{CI}-5.88$ to 4.48), but CIs include a possible modest benefit and a possible modest detriment of n-3PUFAs compared with antidepressants. Adverse events were reported only as number of events experienced as opposed to number of individuals experiencing at least one event, so could not be analysed.

\section{DISCUSSION}

\section{Summary of main results}

Studies were found comparing the impact of n-3PUFAs for MDD to placebo (25 studies, involving 1438 participants), and to antidepressant treatment (1 study involving 40 participants). For the placebo comparison, there was a small-to-modest beneficial effect of n-3PUFAs on

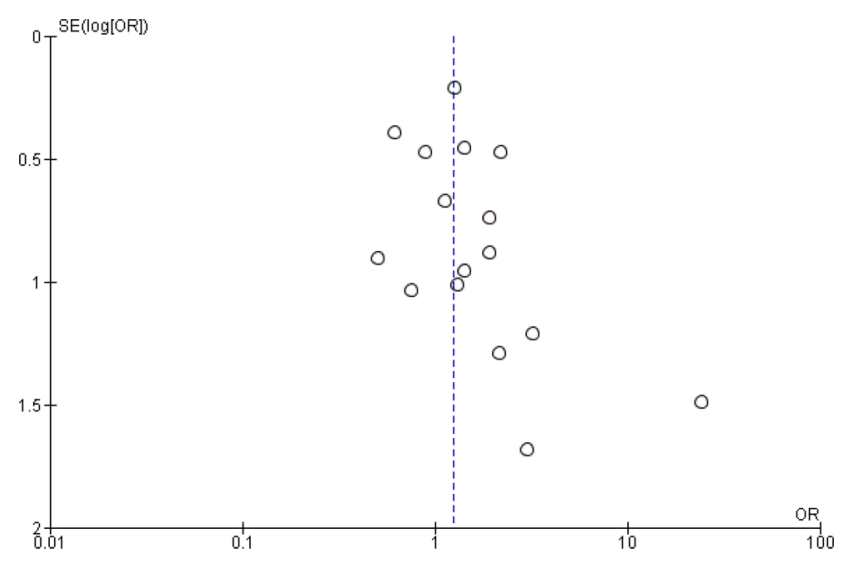

Figure 6 Funnel plot for the outcome adverse events for the comparison of $n-3$ polyunsaturated fatty acids with placebo. depressive symptomology, compared with placebo (the equivalent of approximately 2.2 (95\% CI 0.8 to 3.6) HDRS points). National Institute for Health and Care Excellence (NICE) ${ }^{65}$ has previously suggested a reduction in HDRS score of three points or more to demonstrate clinical significance, thus the clinical significance of the effect from this meta-analysis is small. Our CIs do not exclude a clinically meaningful effect, but also include a negligible effect at the lower end. Numbers of individuals experiencing adverse events were similar between intervention and placebo groups, although wide CIs suggest that effects could range from a small reduction to a modest increase in n-3PUFA groups compared with placebo. For the comparison with antidepressants, no differences between treatment with n-3PUFAs and treatment with antidepressants were found in depressive symptomology.

\section{The evidence available}

The evidence for all outcomes for both comparisons was judged to be low-to-very low using GRADE criteria. For both comparisons and all outcomes, the evidence is limited and highly heterogeneous, resulting in findings that are imprecise and potentially biased. The evidence available largely derives from few studies $(n=26)$ and few participants $(\mathrm{N}=1458)$. All studies were directly relevant to our research question, but considerable differences were identified in all aspects of study methodology, and the majority of available studies were small. Almost half of all participants in our analyses derive from only three trials, ${ }^{495256}$ and even using random-effects models, the contribution of these three trials to our overall estimates is high. While these trials were judged to be of low risk of bias on most measures, biases or methodologicalspecific outcomes in these trials may have contributed to our overall result. Our funnel plots also suggest an absence of small studies showing null findings, and sensitivity analyses using fixed-effects models suggest a positive influence from small positive studies in our main analyses. These findings suggest that our overall effect size estimates may be biased towards a positive finding for n-3PUFAs compared with the reality. Sensitivity analyses using only the studies that were judged to be of low risk of bias also suggest bias in our main analyses on depressive symptomology, towards a positive finding for n-3PUFAs. These analyses report smaller effect sizes than those found in our main analyses, and CIs include the possibility of no differences between groups. This evidence, alongside that of the funnel plots and the findings using fixed-effects models suggest that the true effect of n-3PUFAs is likely to be smaller than that reported in our main analyses. Imprecise effect size estimates were found for all outcomes. In all analyses, possible effects range from negligible effects to important clinical benefits. While this imprecision does not rule out clinically relevant effects, considerable caution must be used in interpreting all effect size estimates, and further evidence, in the form of adequately powered 
well-designed trials, is clearly required before firm conclusions can be drawn. Findings in our primary outcome of depressive symptomology also demonstrate considerable evidence of heterogeneity. This heterogeneity was not explained by prespecified subgroups, nor by consideration of study methodology or our decisions for analyses. An effect based on the sole use of EPA may be suggested, but the evidence is very limited. Further work is again required. For the comparison with antidepressant treatment, only one small study was available, and this study was given judgements of high risk of bias in many domains. Inconsistency in trial reporting for both comparisons was obvious.

\section{Strengths and weaknesses of the review}

The findings of this review may be biased due to the bias in the evidence available-only a limited number of studies were available for assessing outcomes for either comparison, and there was a high relative weighting in all analyses for the placebo comparison from three trials of high quality. The review process also may have been biased. Our searches were more likely to detect articles published in English and in mainstream journals. We were also unable to contact authors of some articles that may have been relevant. Reliance on available data also meant that only limited studies could contribute to certain analyses. We did not attempt to gain participant-level data from study authors, nor did we attempt more complex analyses than those detailed. We relied on authors of existing relevant studies or trial registrations to also inform us of unpublished studies. Our searches covered relevant conference-based publications, but we made no further attempts to find or identify unpublished literature.

\section{Agreements and disagreements with other reviews}

Many published reviews and meta-analyses investigating a role for n-3PUFAs for depression compared with placebo are available. ${ }^{27-35}$ Many of these reviews focus also on RCTs, but typically use a broader definition of depressive disorder, and the relevance of some studies included in these reviews has been debated. ${ }^{66}$ These published reviews largely provide a combined estimate that is similar to that achieved in our analyses, although our interpretation is more conservative, through consideration of clinical significance and possible effects demonstrated by CIs. All reviews are based on the same very limited pool of studies, and report substantial heterogeneity between studies and high probability of bias. Interestingly, our effect size estimates are also comparable to some degree to those suggested by recent meta-analyses on the effects of antidepressants for MDD, compared with placebo. ${ }^{67-69}$ CIs, however, suggest more precise small-to-modest effects for antidepressants, while our CIs suggest an effect that may range from negligible to modest.

\section{CONCLUSIONS}

At present, we do not have sufficient good quality evidence to determine the effects of n-3PUFAs as a treatment for MDD. Our primary analyses suggest a small-to-modest, non-clinically relevant benefit of n-3PUFAs on depressive symptomology compared with placebo, although the effect size estimate is imprecise, and the quality of the evidence on which this result is based is very low and highly biased. Sensitivity analyses, funnel plot inspection and comparison of our results with those of large well-conducted trials also suggest that this effect size estimate is likely to be biased towards a positive finding for n-3PUFAs, and that the true effect is likely to be smaller. Our data do suggest similar rates of adverse events in n-3PUFA and placebo groups, although the evidence is again of very low quality. The one study that directly compares n-3PUFAs with antidepressants in our review finds comparable benefit, but the quality of the evidence here is very low. Given the high rates of adverse events associated with some antidepressants, n-3PUFAs may offer an alternative treatment of possible benefit and reduced side effects, but more evidence regarding both the potential positive and negative effects of n-3PUFAs for MDD is required before such a suggestion can be advocated.

More adequately powered, well-designed trials are required to increase the evidence base, and explore particularly the heterogeneity found between studies. Trials that compare n-3PUFAs with usual antidepressant treatment, and studies to investigate differing effects dependent on individual characteristics and study methodology are particularly important. Mechanistic studies are also preferentially required, to identify the mechanisms both for the development and treatment of MDD, and the possible actions in these pathways for n-3PUFAs.

Acknowledgements This work was supported by Bournemouth University, UK; the National Institute for Health Research (NIHR) Biomedical Research Unit in Nutrition, Diet and Lifestyle at the University Hospitals Bristol NHS Foundation Trust and the University of Bristol, the University of Bristol, UK; and the Cochrane Depression, Anxiety and Neurosis Group, in terms of staff time.

Contributors All authors contributed to the writing of the Cochrane protocol and review. For the review, HMS and RP screened all articles identified by searches, and extracted data from all eligible studies. KMA also extracted data from all eligible studies. KMA, HMS and RP collectively resolved disagreements. HMS and RP entered all data into Review Manager V.5. KMA checked all entered data, conducted all analyses and wrote up the review. All authors (KMA, HMS, RP, ARN, RC) provided intellectual input, and checked and revised the review. KMA wrote this abridged version. All authors (KMA, HMS, RP, ARN, RC) provided intellectual input for the abridged version, and checked and subsequently revised this draft.

Funding The National Institute for Health Research (NIHR) is the largest single funder of the Cochrane Depression, Anxiety and Neurosis Group.

Disclaimer The views and opinions expressed herein are those of the authors and do not necessarily reflect those of the NIHR, National Health Service (NHS) or the Department of Health.

Competing interests None declared. 
Ethics approval Bournemouth University Research Ethics Committee.

Provenance and peer review Not commissioned; externally peer reviewed.

Data sharing statement No additional data are available.

Open Access This is an Open Access article distributed in accordance with the Creative Commons Attribution Non Commercial (CC BY-NC 4.0) license, which permits others to distribute, remix, adapt, build upon this work noncommercially, and license their derivative works on different terms, provided the original work is properly cited and the use is non-commercial. See: http:// creativecommons.org/licenses/by-nc/4.0/

\section{REFERENCES}

1. American Psychiatric Association. Diagnostic and Statistical Manual of Mental Disorders. 5th edn. Washington DC: American Psychiatric Association, 2013.

2. World Health Organization. Global Burden of Disease. http://www. who.int/healthinfo/global_burden_disease/gbd/en/index.html 1 Febuary 2014.

3. Haag M. Essential fatty acids and the brain. Can J Psychiatry 2003;48:195-203.

4. Ruxton CHS, Calder PC, Reed SC, et al. The impact of long chain n-3 polyunsaturated fatty acids on human health. Nutr Res Rev 2005;18:113-29.

5. Ma J, Folsom AR, Eckfeldt JH, et al. Short- and long-term repeatability of fatty acid composition of human plasma phospholipids and cholesterol esters. The Atherosclerosis Risk in Communities (ARIC) Study Investigators. Am J Clin Nutr 1995:62:572-8.

6. British Nutrition Foundation. BNF Briefing paper: $n-3$ fatty acids and health. London: British Nutrition Foundation, 1999.

7. James MJ, Gibson RA, Cleland LG. Dietary polyunsaturated fatty acids and inflammatory mediator production. Am J Clin Nutr 2000;71:343s-8s.

8. Hibbeln JR. Fish consumption and major depression. Lancet 1998;351:1213.

9. Silvers KM, Scott KM. Fish consumption and self-reported physical and mental health status. Public Health Nutr 2002;5:427-31.

10. Tanskanen A, Hibblen JR, Hintikka J, et al. Fish consumption, depression, and suicidality in a general population. Arch Gen Psychiatry 2001;58:512-13.

11. Edwards R, Peet M, Shay J, et al. Depletion of docosahexaenoic acid in red blood cell membranes of depressive patients. Biochem Soc Trans 1998;26:S142.

12. Peet M, Murphy B, Shay J, et al. Depletion of omega-3 fatty acid levels in red blood cell membranes of depressive patients. Biol Psychiatry 1998;43:315-19.

13. Nemets B, Stahl Z, Belmaker RH. Addition of omega-3 fatty acid to maintenance medication treatment for recurrent unipolar depressive disorder. Am J Psychiatry 2002;159:477-9.

14. Su KP, Huang SY, Chiu CC, et al. Omega-3 fatty acids in major depressive disorder-a preliminary double-blind placebo-controlled trial. Eur Neuropsychopharmacol 2003;13:267-71.

15. Frangou S, Lewis M, McCrone P. Efficacy of ethyl-eicosapentaenoic acid in bipolar depression: randomised double-blind placebo-controlled study. Br J Psychiatry 2006;188:46-50.

16. Stoll AL, Severus WE, Freeman MP, et al. Omega-3 fatty acids in bipolar disorder-a preliminary double-blind, placebo-controlled trial. Arch Gen Psychiatry 1999;56:407-12.

17. Hakkarainen R, Partonen T, Haukka J, et al. Is low dietary intake of omega-3 fatty acids associated with depression? Am J Psychiatry 2004;161:567-9.

18. Miyake $\mathrm{Y}$, Sasaki S, Yokoyama T, et al. Risk of postpartum depression in relation to dietary fish and fat intake in Japan: the Osaka Maternal and Child Health Study. Psychol Med 2006;36:1727-35.

19. Appleton KM, Peters TJ, Hayward RC, et al. Depressed mood and $\mathrm{n}-3$ polyunsaturated fatty acid intake from fish: non-linear or confounded association? Soc Psychiatry Psychiatr Epidemiol 2007;42:100-4.

20. Appleton KM, Gunnell D, Peters TJ, et al. No clear evidence of an associations between plasma concentrations of $n-3$ long chain polyunsaturated fatty acids and depressed mood in a non-clinical population. Prostaglandins Leukot Essent Fatty Acids 2008;78:337-42

21. Browne JC, Scott KM, Silvers KM. Fish consumption in pregnancy and omega-3 status after birth are not associated with postnatal depression. J Affect Disord 2006;90:131-9.
22. Mamalakis G, Kiriakakis M, Tsibinos G, et al. Depression and adipose polyunsaturated fatty acids in an adolescent group. Prostaglandins Leukot Essent Fatty Acids 2004;71:289-94.

23. Grenyer BFS, Crowe T, Meyer B, et al. Fish oil supplementation in the treatment of major depression: a randomised double-blind placebo-controlled trial. Prog Neuro Psychopharmacol Biol Psychiatry 2007:31:1393-6.

24. Silvers KM, Woolley CC, Hamilton FC, et al. Randomised double-blind placebo-controlled trial of fish oil in the treatment of depression. Prostaglandins Leukot Essent Fatty Acids 2005;72:211-18.

25. Keck PE Jr, Mintz J, McElroy SL, et al. Double-blind, randomized, placebo-controlled trials of ethyl-eicosapentanoate in the treatment of bipolar depression and rapid cycling bipolar disorder. Biol Psychiatry 2006;60:1020-2.

26. Rogers PJ, Appleton KM, Kessler D, et al. No effect of n-3 long chain polyunsaturated fatty acid (EPA and DHA) supplementation on depressed mood and cognitive function: a randomized controlled trial. Br J Nutr 2008;99:421-31.

27. Appleton KM, Hayward RC, Gunnell D, et al. Effects of n3 long chain polyunsaturated fatty acids on depressed mood: systematic review of published trials. Am J Clin Nutr 2006;84:1308-16.

28. Appleton KM, Rogers PJ, Ness AR. Is there a role for $n-3$ long-chain polyunsaturated fatty acids in the regulation of mood and behaviour? A review of the evidence to date from epidemiological studies, clinical studies and intervention trials. Nutr Res Rev 2008;21:13-41.

29. Appleton KM, Rogers PJ, Ness AR. Updated systematic review and meta-analysis of the effects of $n-3$ long-chain polyunsaturated fatty acids on depressed mood. Am J Clin Nutr 2010;91:757-70.

30. Lin PY, Su KP. A meta-analytic review of double-blind, placebo-controlled trials of anti-depressant efficacy of omega-3 fatty acids. J Clin Psychiatry 2007;68:1056-61.

31. Smith MA, Beilin LJ, Mori TA, et al. Essential fatty acids and mood: a systematic review of observational studies. Am J Food Nutr 2011;1:14-27.

32. Bloch MH, Hannestad J. Omega-3 fatty acids for the treatment of depression: systematic review and meta-analysis. Mol Psychiatry 2012;17:1272-82.

33. Grosso G, Pajak A, Marventano S, et al. Role of omega-3 fatty acids in the treatment of depressive disorders: a comprehensive metaanalysis of randomized clinical trials. PLOS ONE 2014;9:e96905.

34. Martins JG. EPA but not DHA appears to be responsible for the efficacy of omega-3 LC-PUFA supplementation in depression: evidence from an updated meta-analysis of randomized controlled trials. Oleagineux Corps Gras Lipides 2011;18:188-98.

35. Sublette ME, Ellis SP, Geant AL, et al. Meta-analysis of the effects of eicosapentaenoic aicd (EPA) in clinical trials in depression. $J$ Clin Psychiatry 2011;72:1577-84.

36. Appleton KM, Perry R, Sallis HM, et al. Omega-3 fatty acids for depression in adults. Cochrane Database Syst Rev 2015;(11): CD004692.

37. Appleton KM, Perry R, Sallis HM, et al. Omega-3 fatty acids for depression in adults. Cochrane Database Syst Rev 2014;(5): CD004692.

38. Higgins JPT, Green S. Cochrane handbook for systematic reviews of interventions. 5.1 edn. Chichester, UK: The Cochrane Collaboration \& John Wiley \& Sons, Ltd, 2011.

39. Deeks JJ, Altman DG, Bradbrun MJ. Statistical methods for examining heterogeneity and combining results from several studies in meta-analysis. In: Egger M, Davey Smith G, Altman DG, eds. Systematic reviews in health care: meta-analysis in context. London: BMJ Publishing Group, 2001:285-312.

40. Egger M, Davey Smith G. Principles of and procedures for systematic reviews. In: Egger M, Davey Smith G, Altman DG, eds. Systematic reviews in health care: meta-analysis in context. London: BMJ Publishing Group, 2001:23-42.

41. Sterne JAC, Egger M, Davey Smith G. Investigating and dealing with publication and other biases. In: Egger M, Davey Smith G, Altman DG, eds. Systematic reviews in health care: meta-analysis in context. London: BMJ Publishing Group, 2001:189-208.

42. Furukawa TA, Barbui C, Cipriani A, et al. Imputing missing standard deviations in meta-analyses can provide accurate results. J Clin Epidemiol 2006;59:7-10.

43. Higgins JPT, Thompson SG. Quantifying heterogeneity in a meta-analysis. Stat Med 2002;21:1539-58.

44. Higgins JPT, Thompson SG, Deeks JJ, et al. Measuring inconsistency in meta-analyses. BMJ 2003;327:557-60.

45. Lucas M, Asselin G, Mérette C, et al. Ethyl-eicosapentaenoic acid for the treatment of psychological distress and depressive symptoms in middle-aged women: a double-blind, placebo-controlled, randomized clinical trial. Am J Clin Nutr 2009;89:641-51. 
46. Coryell WH. Essential Fatty Acids for Major Depression. http:// clinicaltrials.gov/show/NCT00256412 (Accessed 22 Jul 2014).

47. da Silva TM, Munhoz RP, Alvarez C, et al. Depression in Parkinson's disease: a double-blind, randomized, placebo-controlled pilot stud of omega-3 fatty-acid supplementation. J Affect Disord 2008;111:351-9.

48. Jazayeri S, Tehrani-Doost M, Keshavarz SA, et al. Comparison of therapeutic effects of omega-3 fatty acid eicosapentaenoic acid and fluoxetine, separately and in combination, in major depressive disorder. Aust N Z J Psychiatry 2008;42:192-8.

49. Mischoulon D, Nierenberg AA, Schettler PJ, et al. A double-blind randomized controlled clinical trial comparing eicosapentaenoic acid versus docosahexaenoic acid for depression. J Clin Psychiatry 2015;76:54-61.

50. Peet M, Horrobin DF. A dose-ranging study of the effects of ethyl-eicosapentaenoate in patients with ongoing depression despite apparently adequate treatment with standard drugs. Arch Gen Psychiatry 2002;59:913-19.

51. Bot M, Pouwer F, Assies J, et al. Eicosapentaenoic acid as an add-on to antidepressant medication for co-morbid major depression in patients with diabetes mellitus: a randomized, double-blind placebo-controlled study [ISRCTN30877831; NTR624]. J Affect Disord 2010;126:282-6.

52. Carney RM, Freedland KE, Rubin EH, et al. Omega-3 augmentation of sertraline in treatment of depression in patients with coronary heart disease: a randomized controlled trial. JAMA 2009;302:1651-7.

53. Gertsik L, Poland RE, Bresee C, et al. Omega-3 fatty acid augmentation of citalopram treatment for patients with major depressive disorder. J Clin Psychopharmacol 2012;32:61-4.

54. Gharekhani A, Khatami MR, Dashti-Khavidaki S, et al. The effect of omega-3 fatty acids on depressive symptoms and inflammatory markers in maintenance hemodialysis patients: a randomized, placebo-controlled clinical trial. Eur J Clin Pharmacol 2014;70:655-65.

55. Gonzalez A, Mata S, Sanchez P, et al. Omega-3 fatty acids as adjunctive of antidepressant therapy and its effects on brain-derived neurotrophic factor in serum, monocytes and lymphocytes. Arch Venezolanos Farmacol Terapeutica 2011;30:72-8.

56. Lesperance F, Frasure-Smith N, St-Andre E, et al. The efficacy of omega-3 supplementation for major depression: a randomized controlled trial [ISRCTN47431149]. J Clin Psychiatry 2011;72:1054-62.
57. Marangell LB, Martinez JM, Zboyan HA, et al. A double-blind, placebo-controlled study of the omega-3 fatty acid docosahexaenoic acid in the treatment of major depression. Am J Psychiatry 2003;160:996-8.

58. Mischoulon D, Papakostas GI, Dording CM, et al. A double-blind, randomized controlled trial of ethyl-eicosapentaenoate for major depressive disorder. J Clin Psychiatry 2009;70:1636-44.

59. Park Y, Park YS, Kim SH, et al. Supplementation of n-3 polyunsaturated fatty acids for major depressive disorder: a randomized double-blind 12- week placebo-controlled trial in Korea. Ann Nutr Metab 2015;66:141-8.

60. Rondanelli M, Giacosa A, Opizzi A, et al. Effect of omega-3 fatty acids supplementation on depressive symptoms and on health-related quality of life in the treatment of elderly women with depression: a double-blind, placebo-controlled, randomized clinical trial. J Am Coll Nutr 2010;29:55-64.

61. Montgomery SA, Asberg M. A new depression scale designed to be sensitive to change. Br J Psychiatry 1979;134:382-9.

62. Hamilton M. A rating scale for depression. J Neurol Neurosurg Psychiatr 1960;23:56-62.

63. Beck AT, Steer RA. Beck Depression Inventory Manual. San Antonio, Texas: Psychological Corporation, 1987.

64. Yesvage JA, Brink TL, Rose TL, et al. Development and validation of a geriatric depression screening scale: a preliminary report. J Psychiatr Res 1982;17:37-49.

65. National Institute for Clinical Excellence. Depression: management of depression in primary and secondary care. London, England: National Institute for Clinical Excellence, 2004.

66. Lin PY, Mischoulon D, Freeman MP, et al. Are omega-3 fatty acids anti-depressants or just mood-improving agents? The effect depends upon diagnosis, supplement preparation, and severity of depression. Mol Psychiatry 2012;17:1161-3; author reply 1163-7.

67. Fountoulakis KN, Veroniki AA, Siamouli M, et al. No role for initial severity on the efficacy of antidepressants: results of a multi-meta-analysis. Ann Gen Psychiatry 2013;12:26.

68. Kirsch I, Deacon BJ, Huedo-Medina TB, et al. Initial severity and antidepressant benefits: a meta-analysis of data submitted to the Food and Drug Administration. PLoS Med 2008;5:e45.

69. Turner EH, Matthews AM, Linardatos E, et al. Selective publication of antidepressant trials and its influence on apparent efficacy. N Engl J Med 2008;358:252-60. 


\section{Correction}

Appleton KM, Sallis HM, Perry R, et al. w-3 fatty acids for major depressive disorder in adults: An abridged Cochrane review. BMJ Open 2016;6:e010172 doi:10.1136/ bmjopen-2015-010172

It has recently transpired that the MADRS scores used in the analyses for our Cochrane review for the trial by Bot et al (2010) were reversed between intervention and placebo groups. These data resulted from correspondence with the authors of this trial and they have recently confirmed an error. Reversal of the data for these groups changes our results minimally, does not change our interpretation of our results and does not change our conclusions.

Changes to the results of all affected analyses (n-3PUFAs vs placebo: depressive symptomology - continuous data) are given in our Cochrane review (Appleton KM, Sallis HM, Perry R, et al. Omega-3 fatty acids for depression in adults. Cochrane Database Syst Rev 2015;11:CD004692). Changes to the analyses included in this abridged publication are as follows:

Main analyses: published result $-\mathrm{SMD}=-0.32(95 \%$ CI -0.52 to -0.12$), \mathrm{I}^{2}=58 \%$; revised result $-\mathrm{SMD}=-0.30(95 \% \mathrm{CI}-0.50$ to -0.10$), \mathrm{I}^{2}=59 \%$. This result represents a difference between groups in scores on the HDRS (17-item) of approximately 2.1 points $(95 \%$ CI 0.7 to 3.5$)$.

Subgroup analyses based on presence/absence of comorbidities: published result $\chi^{2}=7.23, \mathrm{df}=2, \mathrm{p}=0.03, \mathrm{I}^{2}=72 \%$; revised result $-\chi^{2}=6.32, \mathrm{df}=2, \mathrm{p}=0.04, \mathrm{I}^{2}=68 \%$. Subgroup analyses based on presence/absence of adjunctive therapies: published result $-\chi^{2}=1.01, \mathrm{df}=2, \mathrm{p}=0.60, \mathrm{I}^{2}=0 \%$; revised result $-\chi^{2}=1.46, \mathrm{df}=2, \mathrm{p}=0.48, \mathrm{I}^{2}=0 \%$.

Sensitivity analyses using fixed effects models: published result $-\mathrm{SMD}=-0.20(95 \%$ CI -0.31 to -0.09$)$; revised result $-\mathrm{SMD}=-0.19(95 \%$ CI -0.30 to -0.08$)$. Sensitivity analyses based on selection bias: published result $-\mathrm{SMD}=-0.21$ (95\% CI -0.45 to $0.03)$; revised result $-\mathrm{SMD}=-0.18$ (95\% CI -0.42 to 0.06$)$. Sensitivity analyses based on performance bias: published result $-\mathrm{SMD}=-0.14$ (95\% CI -0.55 to 0.26$)$; revised result $-\mathrm{SMD}=-0.07(95 \% \mathrm{CI}-0.48$ to 0.35$)$.

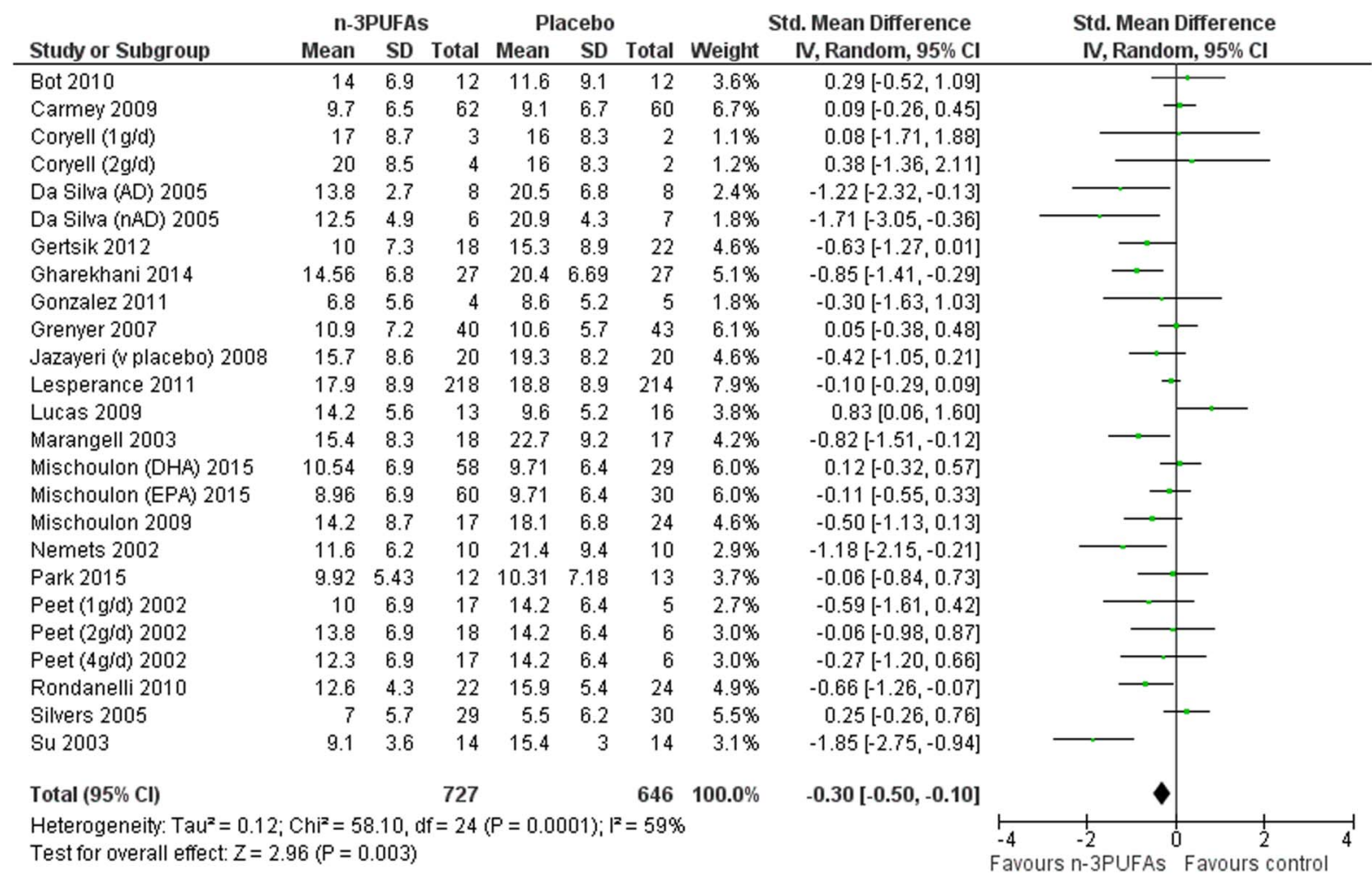

Figure 3 Forest plot for the outcome depressive symptomology (continuous) for the comparison of n-3PUFAs with placebo. 
Additional sensitivity analyses based on use of a treatment that was solely EPA: published result $-\mathrm{SMD}=-0.45$ (95\% CI -0.74 to -0.15$)$; revised result $-\mathrm{SMD}=-0.37$ (95\% CI -0.66 to -0.08$)$.

Figure 3 and Figure 5 also change accordingly. Please see corrected figures below.

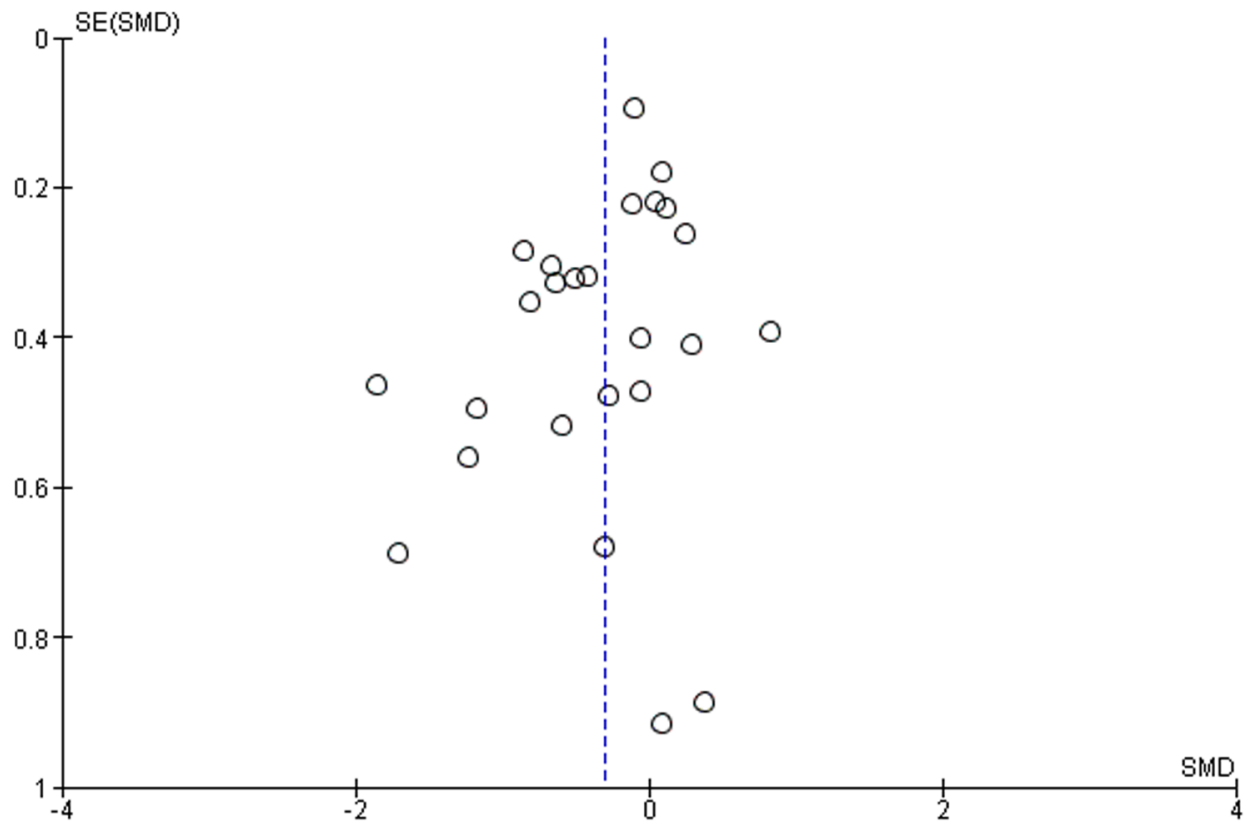

Figure 5 Funnel plot for the outcome depressive symptomology (continuous) for the comparison of $n-3$ polyunsaturated fatty acids with placebo.

Open Access This is an Open Access article distributed in accordance with the Creative Commons Attribution Non Commercial (CC BY-NC 4.0) license, which permits others to distribute, remix, adapt, build upon this work noncommercially, and license their derivative works on different terms, provided the original work is properly cited and the use is non-commercial. See: http://creativecommons.org/licenses/by-nc/4.0/

BMJ Open 2017;7:010172corr1. doi:10.1136/bmjopen-2015-010172corr1

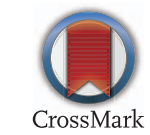

